\title{
Model experiments to assess effect of cavities on bearing capacity of two interfering superficial foundations resting on granular soil
}

https://doi.org/10.2478/sgem-2019-0046

received October 4, 2019; accepted April 16, 2020.

\begin{abstract}
The objective of this paper is to describe the effect of cavities on the bearing capacity of two interfering footings based on granular soil using an exclusively experimental approach with a test model designed in the laboratory. The experimental protocol was carried out based on the variation of several parameters such as the spacing $(x)$ (axis to axis) between the footings, and the distance $(\mathrm{H})$ between the footings and cavities and between the cavities axes (L). The results highlight the effect of cavities and the interference of two strip footings on the bearing capacity factor $(q)$ and efficiency factor $(\mathrm{EF})$. Moreover, the results revealed that, in the case wherein the distance between the footings and the cavity is greater than 3 , the cavity impact is eliminated.
\end{abstract}

Keywords: Bearing capacity; shallow foundations; cavities; interference effect; model test; granular soil.

\section{Introduction}

In recent years, the development of the construction sector in Algeria has rapidly evolved. However, urban projects and structures are still concentrated in densely populated areas. This means that the foundations, which are the lowest parts of civil engineering works, transmit the applied loads to the soil or lower rock.

The vast majority of relevant studies focus on the bearing capacity of an isolated foundation in homogeneous soil. Additionally, existing studies -

\footnotetext{
*Corresponding author: Rafik Boufarh, Department of Civil Engineering, Faculty of Sciences and Technology, Larbi Tebessi University, Tebessa, Algeria, E-mail: rafik.boufarh@univ-tebessa.dz Djamel Saadi, Khelifa Abbeche, Research laboratory in hydraulic applied LARHA, Department of Civil Engineering, Faculty of Technology, University of Batna 2, Batna, Algeria
}

namely the studies of Vesic,, ${ }^{[25]}$ Terzaghi, ${ }^{[22]}$ Meyerhof, ${ }^{[17]}$ and Hansen ${ }^{[8]}$ - were based on the studies of Prandt ${ }^{[18]}$ and Reissner. ${ }^{[19]}$ Moreover, some studies are based on the effect of interference on the bearing capacity of adjacent footings, which was theoretically investigated by Stuart ${ }^{[21]}$ and West and Stuart ${ }^{[26]}$ using the limit equilibrium method and method of constraint characteristics.

Several studies have investigated the effect of footing interference on bearing capacity. Such as, Boufarh et al. ${ }^{[4]}$ experimentally investigated the effect of interference of two strip footings resting on a bilayer soil, and concluded that the efficiency factor is proportional to the internal friction angle of the ground of the first layer, particularly when the foundations are very close, because the increase of the angle of friction causes the expansion of the shear zone under the foundations. Gupta and Sitharam ${ }^{[7]}$ conducted experimental and numerical studies on the interference of sand-based square footings, and concluded that the maximum interference effect is observed in the case wherein the spacing between the footings was $0.5 \mathrm{~B}$, and was approximately negligible in the case wherein the spacing between the footings was equal to $2 \mathrm{~B}$, which $B$ is the width of the footing. The same study developed numerical simulations that were related by the effects of the angle of friction and the expansion on the interference factor. Griffiths et al. ${ }^{[6]}$ carried out a parametric study for the bearing capacity of two rigid and rough strip footings on a soil deposit with randomly varying undrained shear strength. In this study, finite element analysis was combined with random field theory through a Monte Carlo simulation. The obtained results revealed that the effect of the footing interference increased with the soil variability and spatial correlation length. Kumar and Ghosh ${ }^{[12]}$ used upper bound limit analysis to determine the interference effect of two nearby strip footings on sand. They found a solution to the failure mechanism and calculated the bearing capacity under plane strain. Kumar and Bhoi ${ }^{[11]}$ investigated the interference of multiple strip footings on sand using small scale models, and performed a series 
of tests on a scale model. These tests were performed by varying the horizontal distance between the footings to observe its effect on the failure load of a foundation. Lee and Eun ${ }^{[14]}$ investigated a method for estimating the bearing capacity of strip footings resting on the surface of granular soil in various configurations. The results revealed that the limit load of the three footings was similar to that of an isolated footing when the spacing was greater than three times the width of the footing. Acharyya and Dey ${ }^{[1]}$ have also investigated the bearing capacity of the interfering strip footings by focusing on their bearing capacity near a sloping surface using artificial neural networks. In this study, numerical analysis was carried out using Plaxis 3D to estimate the influence of various geotechnical and geometric parameters on the ultimate bearing capacity of the superimposed strip footings located at the top of a natural soil slope. Mabrouki et al. ${ }^{[16]}$ conducted a numerical study using the FLAC finite difference code to estimate the bearing capacity of two juxtaposed strip footings. The interference effect was estimated by considering the efficiency factors for several soil types.

Furthermore, the analysis of some authors' results, in particular, Das and Larbi-Cherif , ${ }^{[5]}$ Kumar and Ghosh, ${ }^{[12]}$ and Mabrouki et al. ${ }^{[16]}$ revealed lower yields compared with those predicted by the theoretical of Stuart, which assumes that the geometry of the failure surface in the soil mass is similar to that considered by Terzaghi. ${ }^{[22]}$.

In engineering practice, the underground cavities of rigid surface constructions, such as dams, pavements, and bridges, require particular attention because underground voids, which generally form owing to tunnel or cavity excavation in soluble rock, can cause structural damage. Studies on the stability of foundations over cavities are rare. Namely, Xiao et al. ${ }^{[27]}$ investigated the undrained stability of a strip footing over voids based on a clay bilayer. This study was based on the numerical analysis of the undrained bearing capacity, and concluded that the rupture mechanisms for a single void can be classified into three categories: the rupture of the upper void surface, combined top surface failure and lateral void, and failure without void collapse. Zhang et al. ${ }^{[28]}$ investigated the collapse of the superficial surface of deep circular cavities in articulated rock masses using adaptive finite element analysis. In this context, a parametric study was conducted to investigate the effects of the Hoek-Brown parameters on the stability factor and rupture mechanism of underground cavities. The obtained results revealed that the Hoek-Brown parameters have different effects on the shape of the superficial surface. Kapoor et al. ${ }^{[9]}$ investigated the effect of a cavity on the bearing capacity of a shallow foundation in geogrid-reinforced soil. Several cases were analyzed to examine the impact of different parameters, such as the layer spacing, cavity position, cavity size on bearing capacity, and settlement of the footing, to examine the improvement produced by geogrid layers. This study concluded that an increase in the diameter of the cavity will lead to the obvious reduction of the foundation's load capacity to a constant cavity depth relative to the width of the footing. Al-Jazaairry and Sabbagh ${ }^{[2]}$ investigated the effect of two cavities on an axially loaded isolated pile resting on a clay layer. This study conducted a simulation to numerically identify the behavior of the pile subjected to axial loading in clay soil and between two cavities. Subsequently, a parametric investigation was carried out to examine the influence of parameters such as the cavity size, spacing, depth, and eccentricity of twin cavities with respect to the pile. The study concluded that the presence of cavities in soil mass reduces the ultimate capacity of the pile. This reduction differs depending on the size and location of the cavity. Lee et al. ${ }^{[15]}$ numerically investigated the undrained stability of strip footings resting on clay layer and above continuous single and double voids. The obtained results provided a data base for calculating the bearing capacity factors as a function of dimensionless parameters. Additionally, it was found that the bearing capacity is related to the vertical and horizontal distances of the voids and footings, width and height of the cavity, and spacing between two cavities. Finally, this study concluded that, for an isolated void, the bearing capacity factor linearly increases with the vertical and horizontal distances between the voids and the footings to a certain critical void location, beyond which the capacity factor becomes constant. In case of two voids, the bearing capacity factor decreased with reduction of the spacing between the two voids. Kiyosumi et al. ${ }^{[10]}$ experimentally investigated the bearing capacity of a shallow foundation on limestone sedimentary rocks containing voids. They observed three types of failure modes for a single void depending on the size and location of the void: a bearing failure without void collapse, bearing failure with void collapse, and void collapse without bearing failure. For two shallow superimposed voids, the lower void had virtually no influence on the failure mode; therefore, it only had a very minor effect on the reduction of bearing capacity.

This study experimentally investigated the effect of interference on the bearing capacity of two adjacent strip footings on the horizontal surface of a granular soil located above the cavities. The main objective of this study was to reveal the effect of various parameters, such as the spacing ( $\mathrm{x}$ ) (axis to axis) between the footings, vertical 
distance $(\mathrm{H})$ between the footings and the crest cavities, and horizontal distance (L) between the cavities, on the bearing capacity.

\section{Experimental investigation}

\subsection{Test bench}

The test bench used in this study comprised a metal tank with the following internal dimensions: length of $2.00 \mathrm{~m}$, width of $0.56 \mathrm{~m}$, and height of $1.00 \mathrm{~m}$. One side of the tank was made of $10 \mathrm{~mm}$ thick high strength fiberglass, which allowed us to observe the levels of the different layers and the mechanism of sand failure. The four sides of the tank were prepared and braced with steel. This ensured that the tank was sufficiently rigid to deform under the loading effect applied to the footing model (Fig .1), considering that the length of the test tank must not be less than five times the width of the footing such that the rupture zones are free and the interference with the sides is negligible (Ueno et al. ${ }^{[24]}$ ). The maximum extension of the rupture zone was $2.5 \mathrm{~B}$ on both sides, and 3B below the footing, knowing that $B$ is the footing's width. The length of the footing was approximately equal to the width of the tank to maintain plane strain conditions; both footing model ends were smoothed to minimize the effects of friction with the walls.

In contrast, the installation of the experimental model was sufficiently rigid to keep the plane deformation conditions in the strip footings. During manufacturing, the main consideration was that the load should always be centered during the loading, while the bench dimensions should have no effect on the obtained results. The footing models had the dimension of $10 \times 50 \mathrm{~cm}^{2}$.

The footings used in the laboratory tests were prepared with a steel profile (UPN 100). The loading system was a hydraulic cylinder, and the load on the footings was transmitted using a rigid steel beam. The dial gauges were placed on the beam. When the load was applied, the displacement comparator indicated the settlement, which was considered as the footing settlement.

In the design of the test model, the cavities are made using PVC tube in order to ensure the presence of cavity void. The thickness of PVC used is $02 \mathrm{~mm}$, the exterior diameter is $110 \mathrm{~mm}$ and the length is $558 \mathrm{~mm}$. It is made of plastic with density of $1350-1460 \mathrm{~kg} / \mathrm{m}^{3}$ and a maximum tensile strength of $45 \mathrm{MPa}$. Elongation is from $20 \%$ to $80 \%$, Elastic modulus is $3000 \mathrm{MPa}$.
Table 1: Geotechnical properties of the tested sand.

\begin{tabular}{ll}
\hline Property & Value \\
\hline Specific gravity $\mathrm{G}_{\mathrm{s}}$ & 2.583 \\
Effective particle size $\mathrm{D}_{10}, \mathrm{~mm}$ & 0.094 \\
Mean particle size $\mathrm{D}_{30}, \mathrm{~mm}$ & 0.200 \\
Mean particle size $\mathrm{D}_{60}, \mathrm{~mm}$ & 0.300 \\
Uniformity coefficient $\mathrm{C}_{\mathrm{u}}$ & 3.19 \\
Coefficient of curvature $\mathrm{C}_{\mathrm{c}}$ & 1.42 \\
Maximum dry unit weight $\mathrm{\gamma}_{\mathrm{d}}(\mathrm{max}), \mathrm{KN} / \mathrm{m}^{3}$ & 17.02 \\
Minimum dry unit weight $\mathrm{Y}_{\mathrm{d}}(\mathrm{min}), \mathrm{KN} / \mathrm{m}^{3}$ & 14.51 \\
Peak friction angle $\varphi^{0}$ & 35 \\
\hline
\end{tabular}

\subsection{Materials}

The soil used in this experiment was sand collected in the region of Tebessa in Eastern Algeria. The sand was oven dried at $105^{\circ} \mathrm{C}$ for $24 \mathrm{~h}$, that is, there was no effect from the presence of water (same condition as for the soil medium in the test). Considering the size of the footing model and the effect of the scale factor, the sand used in these tests was relatively fine. The particle size distribution and other characteristics of the sand are listed in Table 1. The angle of friction was determined using the results obtained by direct shear tests on the soil at a relative density of $60 \%$, which is close to the density of soil in the loading tests.

First, the test tank was filled with sand using the precipitation technique. This technique consists of dropping the particles from the sand in free fall with a controlled rate of discharge and a height of fall of $60 \mathrm{~cm}$. The height of free fall was corrected by taking several tests in the tank before starting the tests of the model to reach the required density. The sand was poured into the tank at a thickness of $5 \mathrm{~cm}$ of a height fixed by the technique adapted and in order to obtain uniform compaction of each layer, a smooth steel roller weighing $27 \mathrm{~kg}$ was passed 30 times over a wooden board placed on the upper surface of each layer to maintain the desired density for the experimental model. After filling the tank up to a proper height, the filled surface was leveled. The footings were placed on the sand bed with a predetermined alignment such that the applied loading was vertically transferred to the footing. 

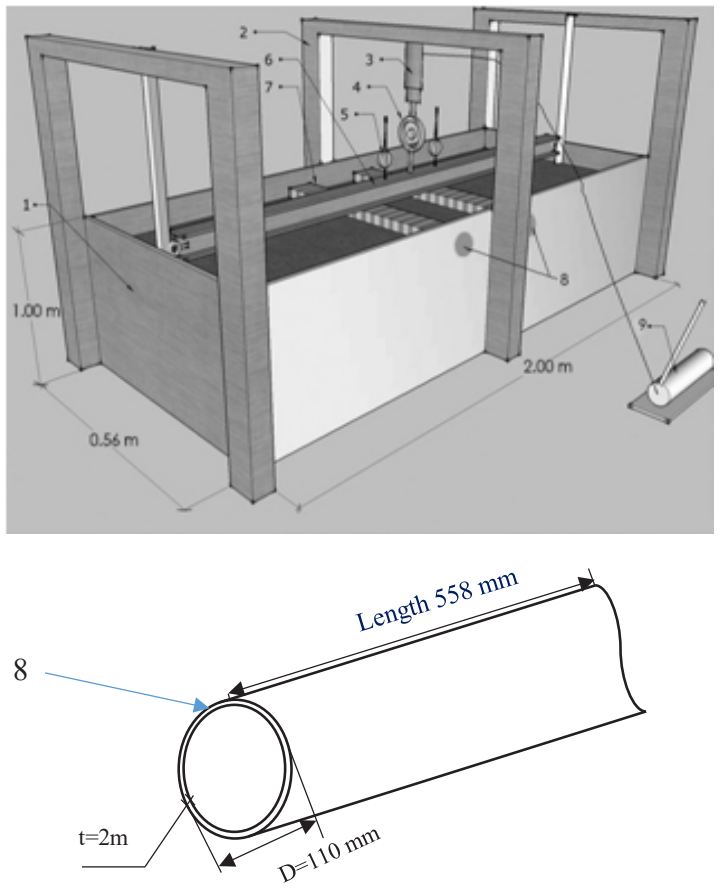

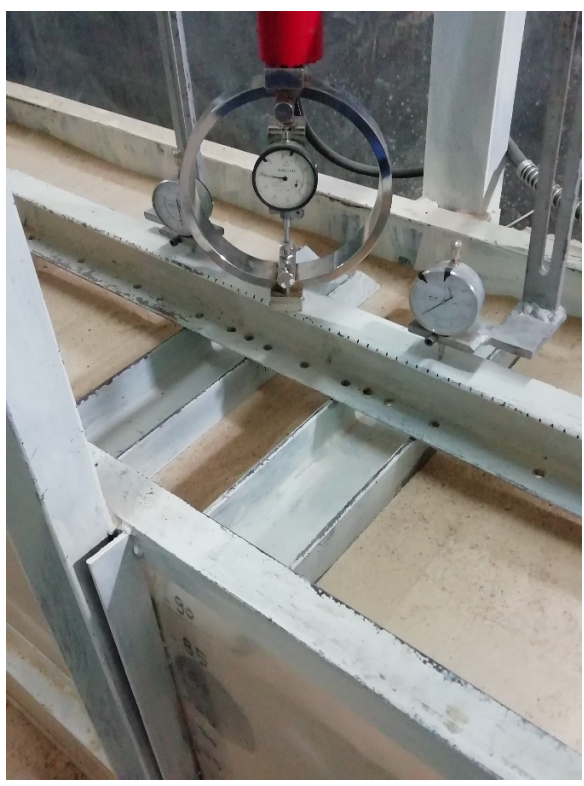

Figure 1: Schematic diagram of test setup: 1) steel test box; 2) steel load frame; 3) hydraulic jack; 4) proving ring; 5) dial gauge; 6) steel beam; 7) model steel footing; 8) cavities (PVC $110 \mathrm{~mm}$ ); 9) roller compactor.

\subsection{Test procedures}

After filling the test tank up to the desired height, the filled surface was leveled and the footings were placed on the sand surface at a predetermined alignment, such that the load could be vertically transferred to the two footings by the beam.

In case of cavities below the footings, the PVC of 110 $\mathrm{mm}$ diameters were placed under the two footings at clearly determined distances according to the analysis tests, and the dial gauges were placed on the beam. The initial reading of the displacement sensor was recorded. Then, the load was applied to the footings at a constant rate and the settlement under the applied load was recorded. Each load increment was maintained until the settlement of the footings stabilized. Then, the settlement was measured from the value recorded on the dial gauges. The load increased until the soil failed and the load displacement curve plot was finally obtained.

\subsection{Test program}

The objective of the experimental laboratory model study was to provide test data with a spacing ratio (x) for footings (axis to axis) ranging from $1 \mathrm{~B}$ to $5 \mathrm{~B}(\mathrm{~B}=10$ $\mathrm{cm}$ footing width). The ratio $(\mathrm{H})$ between the footings and cavities varied from $0.5 \mathrm{H}$ to $3 \mathrm{H}$ considering that $\mathrm{H}=$ B. Additionally, the cavity spacing ratio (L) varied from $0.5 \mathrm{~B}$ to $5 \mathrm{~B}$. Thus, the effect of the cavities on the bearing capacity evolution, and the interference effect of the two adjacent surface strip footings resting on a granular soil (Figure 2), was investigated.

The experimental program used in this study is presented in Table 2.

\section{Results and discussion}

The model tests were conducted under granular soil conditions. The first series of tests was designed to determine the response of the isolated footing resting on the granular sand. The load was incrementally applied until the soil collapse. When the final loading increment was applied, the footing underwent displacement without further load increase.

In this study, the bearing capacity was obtained using the tangent method, which is frequently employed by engineers. Trautmann and Kulhawy ${ }^{[23]}$ used this method to select the load corresponding to a distinctive change in the settlement. This method is also known as the tangent intersection method. When the isolated footing response 
Table 2: Model tests program.

\begin{tabular}{llll}
\hline Test series & X/B & H/B & L/B \\
\hline Without cavity & $1.0,1.5,2.0,2.5,3.0,4.0,5.0$ & $/$ & $/$ \\
With Cavity & $1.0,1.5,2.0,2.5,3.0,4.0,5.0$ & $0.5,1.0,1.5,2.0,2.5,3.0$ & $/$ \\
with two cavities & $1.0,1.5,2.0,2.5,3.0,4.0,5.0$ & $0.5,1.0,1.5,2.0,2.5,3.0$ & $0.5,1.0,1.5,2.0,3.0,4.0,5.0$ \\
\hline
\end{tabular}
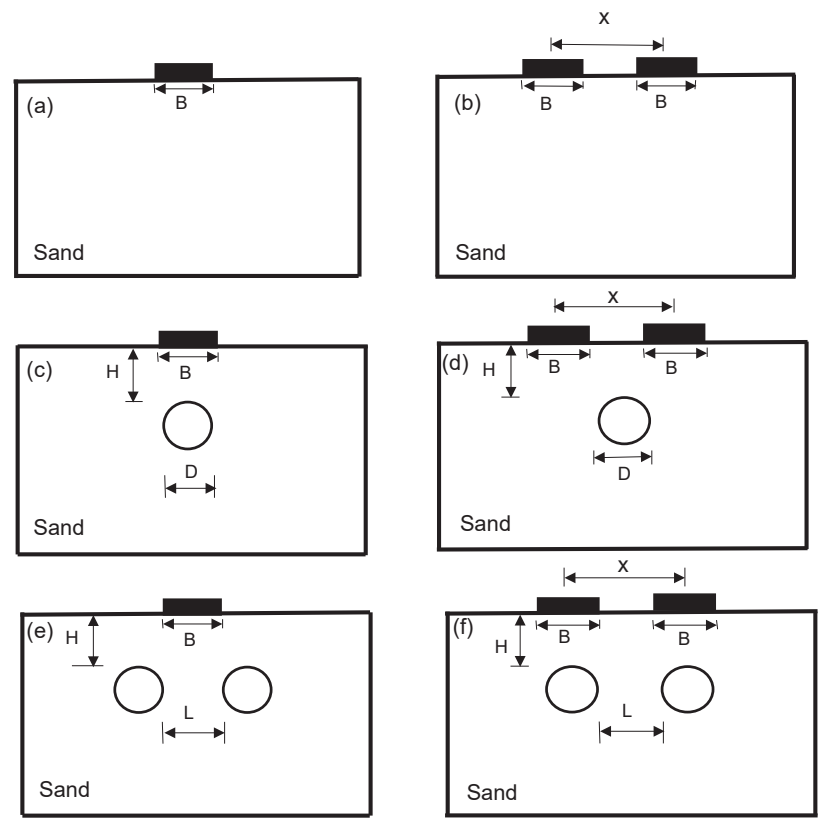

Figure 2: Models used in this study: (a) isolated footing; (b) two adjacent strip footings; (c) isolated footing with cavity; (d) two adjacent strip footings with cavity; (e) isolated footing with two cavities; (f) two adjacent strip footings with two cavities

was determined, two adjacent strip footings were simultaneously loaded to determine their interference behavior.

From the tests listed in Table 2, in the first step, the cases of an isolated footing and the case of two adjacent footings resting on the surface of a sand layer were examined.

As seen in figure 4, the results that were used to determine the load corresponding to the settlement point exhibited a significant slope change and a load corresponding to a distinctive change in the settlement. According to Stuart, ${ }^{[2]}$ the variation in the loadingsettlement curve of the granular soil indicates that the ultimate bearing capacity of the footings reaches the maximum level when the spacing ratios are close to that of one center to another such that $\mathrm{x} / \mathrm{B}=1.25$ and $\mathrm{x} / \mathrm{B}=1.5$

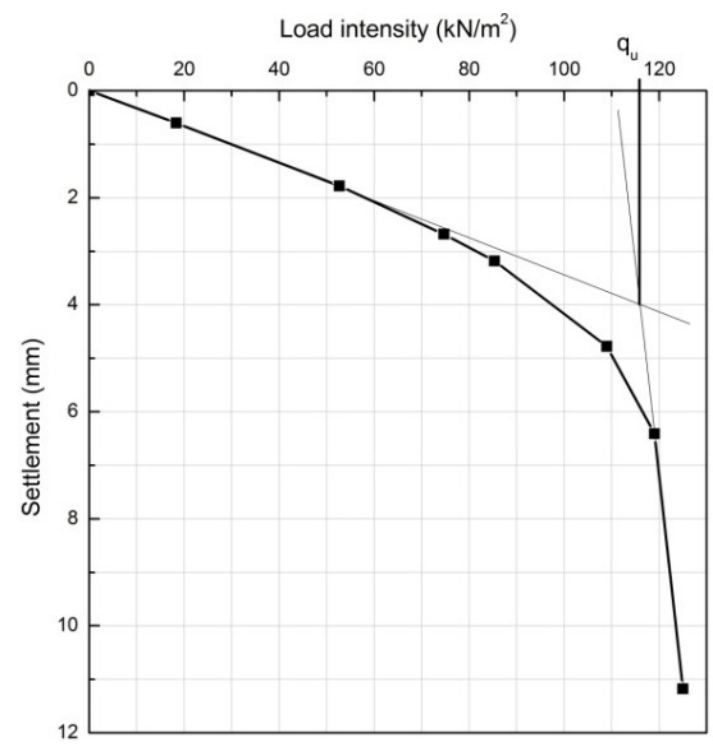

Figure 3: Interpretation of ultimate bearing capacity (qu) by Tangent Intersection Method.

In the second step, the cases of an isolated footing with a cavity $(\mathrm{H} / \mathrm{B}=1)$, and the case of two adjacent footings resting on the surface of a sand layer with a cavity $(\mathrm{H} / \mathrm{B}=1)$ are investigated.

In the third step, the cases of an isolated footing with two cavities $(\mathrm{H} / \mathrm{B}=1$ and $\mathrm{L} / \mathrm{B}=1)$, and the case of two adjacent footings resting on the surface of a sand layer with two cavities $(\mathrm{H} / \mathrm{B}=1$ and $\mathrm{L} / \mathrm{B}=1)$ are studied.

In the fourth step, we compared the three isolated footing cases: the first case is an isolated footing without a cavity; the second case is an isolated footing with a cavity $(\mathrm{H} / \mathrm{B}=1)$; the last case is an isolated footing with two cavities $(\mathrm{H} / \mathrm{B}=1$ and $\mathrm{L} / \mathrm{B}=1)$. All cases rested on the surface of a sand layer.

In the fifth step, we compared the two cases of the adjacent footings: a case of adjacent footings without a cavity, and a case of adjacent footings with a cavity (H/B $=1)$.

Finally, the comparisons between the two cases of adjacent footings were investigated: one case of adjacent 


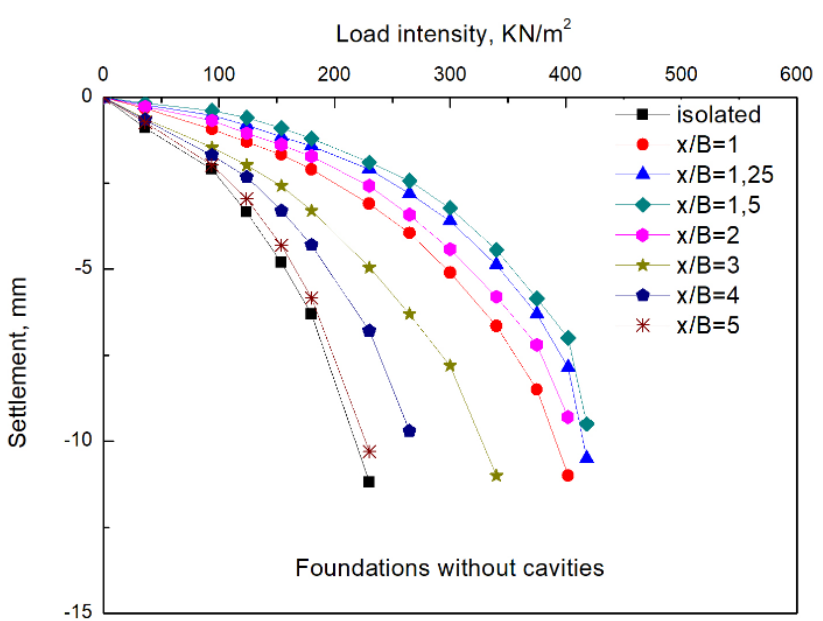

Figure 4: Load-settlement curve for cases of isolated footing and two strip footings; both cases rest on the surface of a sand layer without cavities.

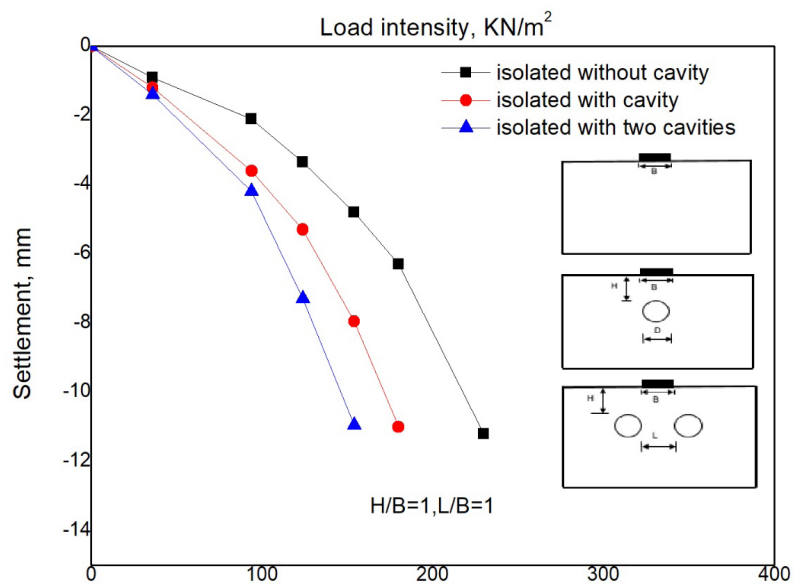

Figure 5: Load-settlement curve of isolated footing without cavity, isolated footing with cavity $(H / B=1)$, and isolated footing with two cavities $(\mathrm{H} / \mathrm{B}=1$ and $\mathrm{L} / \mathrm{B}=1)$.

footings without a cavity, and a case of adjacent footings with two cavities $(\mathrm{H} / \mathrm{B}=1$ and $\mathrm{L} / \mathrm{B}=1)$. Both cases rested on the surface of a sand layer.

The diagrams used in this study comprise a set of results that allow the determination of the granular soil's loading-settlement curve variation. The load-settlement curve for cases of isolated footing and two strip footings; both cases rest on the surface of a sand layer without cavities for various spacing (x/B) are presented in Figs. 4, it was found that the bearing capacity of the footings was maximum when the spacing ratios (interferences) from one center to another (footings) varied in the range of $\mathrm{x} / \mathrm{B}$ $=1.25$ to 1.5 , these results are similar to those obtained by

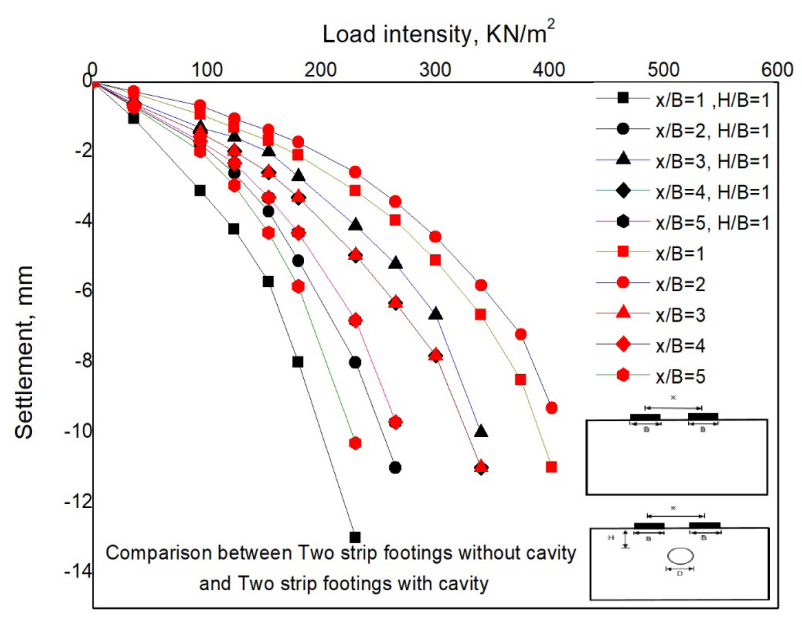

Figure 6: Load-settlement curve of adjacent footings without cavity and case of adjacent footings with cavity $(H / B=1)$.

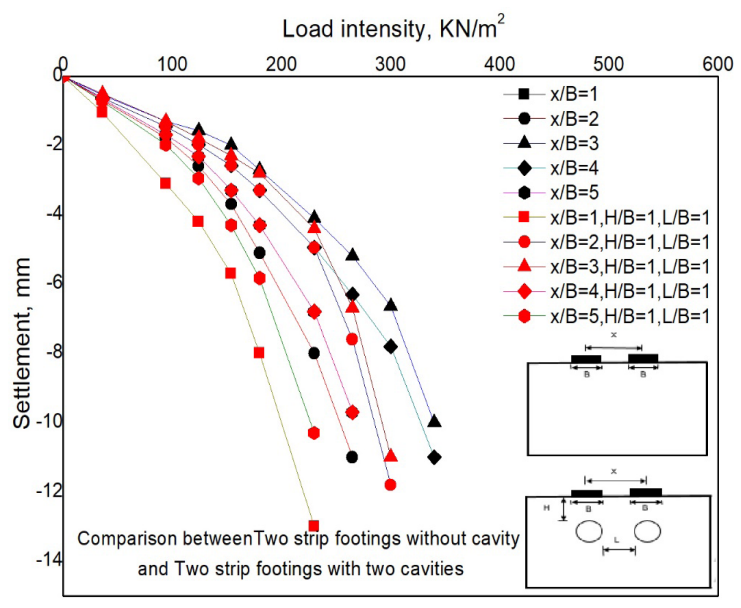

Figure 7: Load-settlement curve of adjacent footings without cavity and case of adjacent footings with two cavities $(H / B=1$ and $L / B=1)$.

(Lee and Eun $\left.{ }^{[14]}\right)$. This reflects the fact that larger footings cause larger settlements compared with smaller footings.

In Figure 5 and Figure 6, the load settlement curve is presented and compared with cases of a single cavity $(\mathrm{H} / \mathrm{B}$ =1), two cavities and without cavity, it is worth noting that the limit load has decreased compared to the three cases. Additionally, the load will be too small to cause maximum settlement or cavity collapse, because the stress is concentrated around the cavity. However, if there are two cavities, the interference of the cavities, that is, the $\mathrm{L} / \mathrm{B}$ ratio, has a direct influence on the settlement.

In the case wherein $\mathrm{L} / \mathrm{B}<3$, it was observed that the interference between the cavities increases up to $\mathrm{L} / \mathrm{B}=1$ 
for the maximum interference, which directly influences the settlement or area of the cavity. The interference between the cavities is considered as a twin cavity (as shown in Figure 7).

The results obtained by this study revealed that the pressure applied to the adjacent strip footings above the twin cavities can be reduced by decreasing the distance between the two cavities to reach a maximum settlement (Lavasan et al. $\left.{ }^{[13]}\right)$. This occurs owing to the interference between the rupture mechanism formed below the footing and the cavities. The bearing capacity is influenced by the location and size of cavities below the footings (Baus and Wang ${ }^{[3]}$. Hence, the load decreases and the settlement increases as the distance between the cavity and the footing becomes shorter. The cavities exert more influence on the settlement when the distance between the adjacent strip footings and the cavities is less than three times the width of the footing.

The analysis of the experimentally obtained results was carried out using the dimensionless parameter called the efficiency factor (EF). This parameter evaluates the interference effect of the implanted footings on the surface of sand. The EF is defined as the ratio of the bearing capacity of an interfered footing $q_{u}$ with or without a cavity to that of an isolated footing with or without a cavity.

$$
E F=\frac{q_{u} \text { interfering }(\text { with cavity, without cavity) }}{q_{u} \text { isolated }(\text { with cavity, without cavity) }}
$$

To verify the values of the bearing capacity factor on the case wherein the adjacent strip footings rested on granular soil, the results of the experimental tests were compared with those of Das and Larbi-Cherif, ${ }^{[5]}$ Stuart, ${ }^{[2]}$ Mabrouki et al., ${ }^{[16]}$ Srinivasan and Ghosh, ${ }^{[20]}$ and Kumar and Ghosh. ${ }^{[12]}$

As can be seen in Figure 8, the interference effect is negligible when the distance between the footings $\mathrm{x} / \mathrm{B}$ $\geq 5$. The maximum efficiency factor variation occurs in cases wherein $\mathrm{x} / \mathrm{B}=1.5$, as confirmed by Das and LarbiCherif, ${ }^{[5]}$ Mabrouki et al. ${ }^{[16]}$ and Srinivasan and Ghosh. ${ }^{[20]}$ The variation of efficiency factors $\mathrm{EF}$ with $\mathrm{x} / \mathrm{B}$ for different H/B values are presented in Figs. 9, 10, 11 and 12.

This figure presents a comparison between the two adjacent footings: the first has a three distance between the cavity and the footings $(\mathrm{H} / \mathrm{B}=1, \mathrm{H} / \mathrm{B}=2$, and $\mathrm{H} / \mathrm{B}=$ 3 ); the second does not have a cavity. In both cases, the $\mathrm{EF}$ reached the maximum value when the distance $\mathrm{x} / \mathrm{B}=$ 1.5. In the case of the adjacent footing without a cavity, and in the case of the footings with a cavity $(\mathrm{H} / \mathrm{B}=3)$, this demonstrates that the cavity influence can be ignored when the distance between the footings and the cavity is

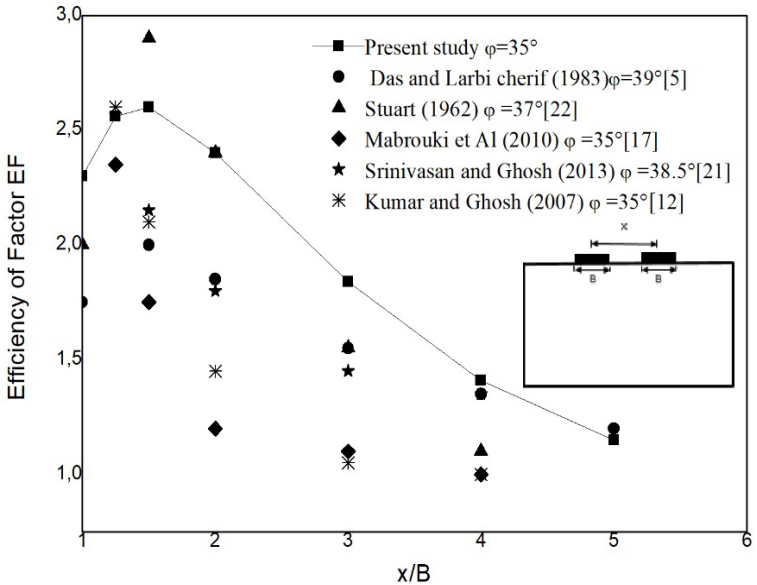

Figure 8: Comparison of EF values of strip footing without cavities with values reported in literature.

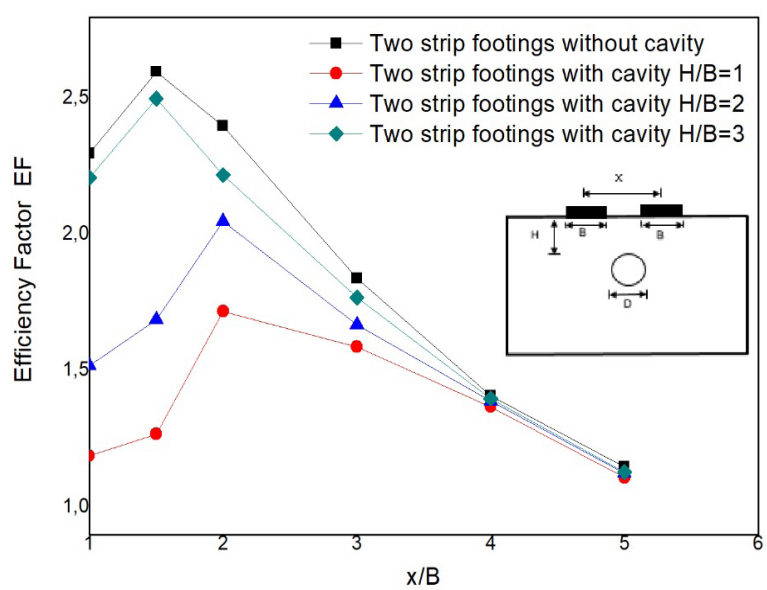

Figure 9: Variation of $E F$ as a function of $x / B$ in the following cases: two strip footings without cavity and with cavity $(H / B=1 ; H / B=2$ and $H / B=3$ ).

$\mathrm{H} / \mathrm{B}=3$. Moreover, the interference effect becomes more pronounced when the convergence between the footings increases. In the two remaining cases, the EF gradually decreased when the cavity was close to the footings, which directly influenced the effect of interference on the footings.

In the case of two adjacent strip footings with two cavities located at $\mathrm{H} / \mathrm{B}=3$, the two distances between the footing's axis $\mathrm{x} / \mathrm{B}$ and between the cavities L/B have been changed each time. The results obtained for the variation of the efficiency factor $\mathrm{EF}$ as a function of $\mathrm{x} / \mathrm{B}$ are presented in Figure 10. It should be noted that the cavities have no influence on the interference between the strip footings, that is, when $\mathrm{H} / \mathrm{B}$ is greater than or equal to three, the cavity effect will be negligible. 


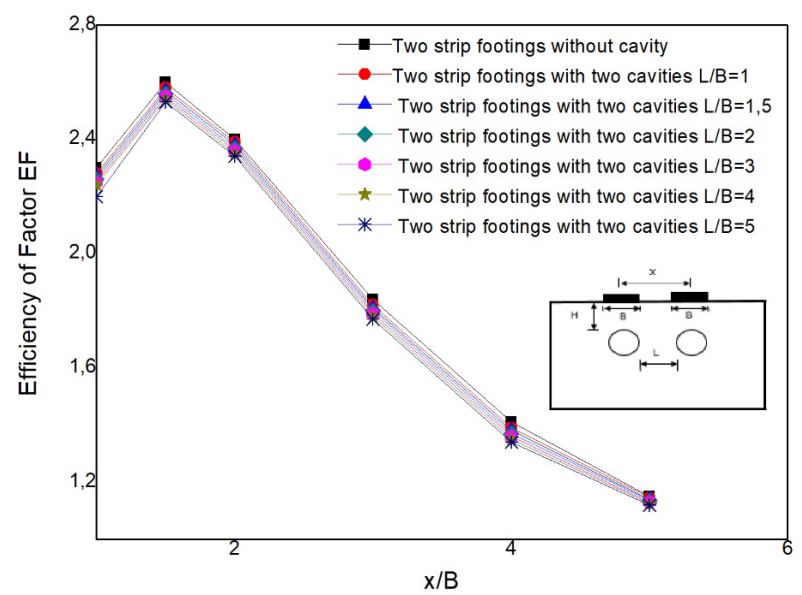

Figure 10: Variation of $\mathrm{EF}$ as a function of $\mathrm{x} / \mathrm{B}$ in the following cases: two strip footings without cavities and with cavity $(\mathrm{H} / \mathrm{B}=3) ;(\mathrm{L} / \mathrm{B}=$ $1.0, \mathrm{~L} / \mathrm{B}=1.5, \mathrm{~L} / \mathrm{B}=2.0, \mathrm{~L} / \mathrm{B}=3.0, \mathrm{~L} / \mathrm{B}=4.0$, and $\mathrm{L} / \mathrm{B}=5.0$ )

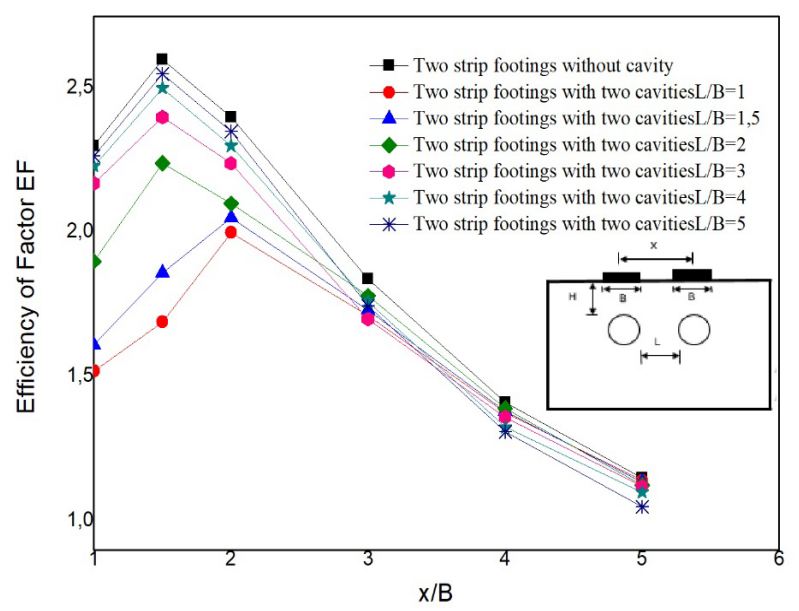

Figure 11: Variation of $E F$ as a function of $x / B$ in the following cases: two strip footings without cavity and with cavity $(\mathrm{H} / \mathrm{B}=2) ;(\mathrm{L} / \mathrm{B}=$ $1.0, \mathrm{~L} / \mathrm{B}=1.5, \mathrm{~L} / \mathrm{B}=2.0, \mathrm{~L} / \mathrm{B}=3.0, \mathrm{~L} / \mathrm{B}=4.0, \mathrm{~L} / \mathrm{B}=5.0)$.

To compare the influence of the convergence of the cavities with footings on $\mathrm{EF}$, the distance between the footings and the cavities was reduced to $H / B=2$, the variation of the $\mathrm{EF}$ as a function of $\mathrm{x} / \mathrm{B}$ are illustrated in Figure 11. The obtained results revealed that the presence of cavities below the footings minimized the $\mathrm{EF}$ and the interference effect between the footings. Also, the convergence between the footings and cavities $(\mathrm{H} / \mathrm{B}=3$ to $H / B=2$ ) decrease the performance of interference effect.

In these tests, the distance between the footings and the cavities of $\mathrm{H} / \mathrm{B}=1$ was selected, and the values of $\mathrm{EF}$ variation as a function of $\mathrm{x} / \mathrm{B}$ were compared with the values of $\mathrm{EF}$ for the strip footings without a cavity in Figure

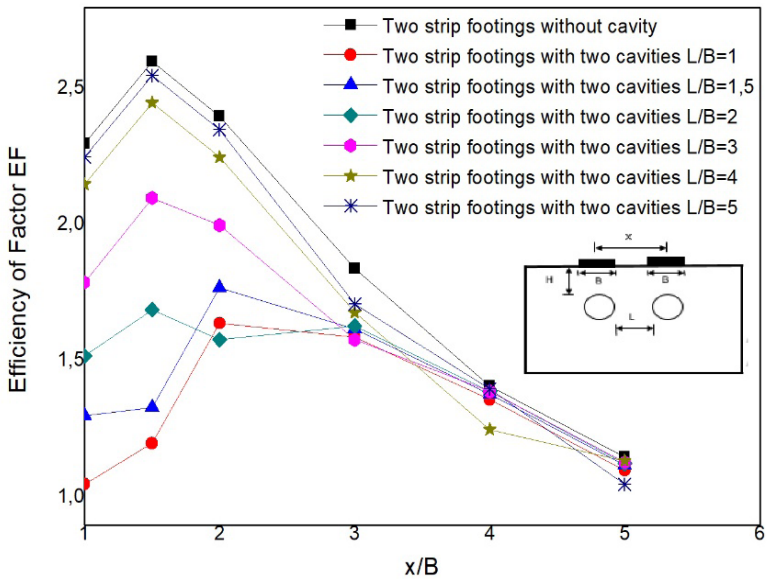

Figure 12: Variation of $E F$ as a function of $x / B$ in the following cases: two strip footings without cavity and with cavity $(H / B=1) ;(L / B=$ 1.0, $L / B=1.5, L / B=2.0, L / B=3.0, L / B=4.0$, and $L / B=5.0$ ).

12. A drastic change in $\mathrm{EF}$ results as a function of $\mathrm{x} / \mathrm{B}$ has been observed due to the high convergence between the cavities and the strip footings. Thus, the interference between the footings was ignored.

\section{Conclusion}

In this study, various laboratory scaled model tests were conducted to determine the effect of cavities on the bearing capacity of two interfering superficial foundations resting on granular soil. The following conclusions were drawn based on the test results from this study:

1. In the case of adjacent strip footings without a cavity, the maximum $\mathrm{EF}$ value was approximately equal to three, which corresponds to a spacing of $\mathrm{x} / \mathrm{B}=1.5$.

2. The stability of the footing rests on a granular soil above cavity influenced by several factors, mainly the depth between the footing and the cavity. This stability varies depending on many parameters, including the spacing between the footings, shape, orientation, and underground cavity dimensions.

3. A significant increase in the value of the bearing capacity was observed under the effect of an existing cavity for $\mathrm{H} / \mathrm{B}=3, \mathrm{H} / \mathrm{B}=2, \mathrm{H} / \mathrm{B}=1$, and $\mathrm{H} / \mathrm{B}=0.5$, owing to the concentration of the constraints around the cavity, which will subsequently cause the deformation of the cavity. Under the effect of the cavity, a significant decrease in the bearing capacity has been reported, the bearing capacity is increased with the divergence between the footings and the cavities from $\mathrm{H} / \mathrm{B}=1$ to $\mathrm{H} / \mathrm{B}=3$. The 
effect of the cavity was canceled in the case wherein the ratio $\mathrm{H} / \mathrm{B}>3$.

4. An excessive increase of settlement was caused by the effect of the convergence of the two twinned cavities, which were considered as a single large cavity.

5. In the case wherein a cavity existed below the adjacent footings, the EF values were maximum when the distance was $\mathrm{x} / \mathrm{B}=1.5$, and the distance between the footings and the cavity was $\mathrm{H} / \mathrm{B}=3$, because the cavity effect was ignored. Additionally, the interference effect became more pronounced when the convergence between the footings increased.

6. The obtained results revealed that the presence of cavities below the footings minimized the interference effect between the footings. Also, the convergence between the footings and cavities $(\mathrm{H} / \mathrm{B}=3$ to $\mathrm{H} / \mathrm{B}=2)$ decrease the performance of interference effect.

7. With a distance between the footings and the cavities of $\mathrm{H} / \mathrm{B}=1$, the comparison between the obtained results with the values of the strip footings without cavities demonstrate a drastic change in EF results as a function of $\mathrm{x} / \mathrm{B}$ has been observed due to the high convergence between the cavities and the strip footings. Thus, the interference between the footings was ignored.

Acknowledgment: We thank Edanz Group (www. edanzediting.com/ac) for editing a draft of this manuscript.

\section{References}

[1] Acharyya, R., \& Dey, A. (2018). Assessment of bearing capacity of interfering strip footings located near sloping surface considering artificial neural network technique. Journal of Mountain Science, 15(12), 2766-2780.

[2] Al-Jazaairry, A. A., \& Sabbagh, T. T. (2017). Effect of Twin Cavities on the Axially Loaded Pile in Clay. International Journal of Geotechnical and Geological Engineering, 11(6), 559-564.

[3] Baus, R., \& Wang, M. (1983). Bearing capacity of strip footing above void. Journal of Geotechnical Engineering, 109(1), 1-14.

[4] Boufarh, R., Abbeche, K., \& Abdi, A. (2019). Experimental Investigation of Interference Between Adjacent Footings on Layered Cohesionless Soil. Soil Mechanics and Foundation Engineering, 1-8.

[5] Das, B. M., \& Larbi-Cherif, S. (1983). Bearing capacity of two closely-spaced shallow foundations on sand. Soils and Foundations, 23(1), 1-7.

[6] Griffiths, D., Fenton, G. A., \& Manoharan, N. (2006). Undrained bearing capacity of two-strip footings on spatially random soil. International Journal of Geomechanics, 6(6), 421-427.

[7] Gupta, A., \& Sitharam, T. (2018). Experimental and numerical investigations on interference of closely spaced square footings on sand. International Journal of Geotechnical Engineering, 1-9.

[8] Hansen, J. B. (1970). A revised and extended formula for bearing capacity. Danish Geotechnical Institute Bull., 28, 5-11.

[9] Kapoor, A., Walia, B., \& Singh, C. (2018). Effect of Cavity on Bearing Capacity of Shallow Foundation in Reinforced Soil. Paper presented at the International Conference on Sustainable Waste Management through Design.

[10] Kiyosumi, M., Kusakabe, O., \& Ohuchi, M. (2011). Model tests and analyses of bearing capacity of strip footing on stiff ground with voids. Journal of Geotechnical and Geoenvironmental Engineering, 137(4), 363-375.

[11] Kumar, J., \& Bhoi, M. K. (2008). Interference of multiple strip footings on sand using small scale model tests. Geotechnical and Geological Engineering, 26(4), 469-477.

[12] Kumar, J., \& Ghosh, P. (2007). Upper bound limit analysis for finding interference effect of two nearby strip footings on sand. Geotechnical and Geological Engineering, 25(5), 499-507.

[13] Lavasan, A. A., Talsaz, A., Ghazavi, M., \& Schanz, T. (2016). Behavior of shallow strip footing on twin voids. Geotechnical and Geological Engineering, 34(6), 1791-1805.

[14] Lee, J., \& Eun, J. (2009). Estimation of bearing capacity for multiple footings in sand. Computers and geotechnics, 36(6), 1000-1008.

[15] Lee, J. K., Jeong, S., \& Ko, J. (2014). Undrained stability of surface strip footings above voids. Computers and Geotechnics, 62, 128-135.

[16] Mabrouki, A., Benmeddour, D., Frank, R., \& Mellas, M. (2010). Numerical study of the bearing capacity for two interfering strip footings on sands. Computers and Geotechnics, 37(4), 431-439.

[17] Meyerhof, G. G. (1963). Some recent research on the bearing capacity of foundations. Canadian Geotechnical Journal, 1(1), 16-26.

[18] Prandtl, L. (1921). Hauptaufsätze: Über die eindringungsfestigkeit (härte) plastischer baustoffe und die festigkeit von schneiden. Journal of Applied Mathematics and Mechanics, 1(1), 15-20.

[19] Reissner, H. (1924). Zum erddruckproblem. Paper presented at the Proceedings of first international congress of applied mechanics.

[20] Srinivasan, V., \& Ghosh, P. (2013). Experimental investigation on interaction problem of two nearby circular footings on layered cohesionless soil. Geomechanics and Geoengineering, 8(2), 97-106.

[21] Stuart, J. (1962). Interference between foundations, with special reference to surface footings in sand. Geotechnique, 12(1), 15-22.

[22] Terzaghi, K. (1943). Theoretical Soil Mechanics. New York and London: John Wiley \& Son.

[23] Trautmann, C. H., \& Kulhawy, F. H. (1988). Uplift loaddisplacement behavior of spread foundations. Journal of Geotechnical Engineering, 114(2), 168-184.

[24] Ueno, K., Miura, K., \& Maeda, Y. (1998). Prediction of ultimate bearing capacity of surface footings with regard to size effects. Soils and Foundations, 38(3), 165-178.

[25] Vesic, A. S. (1973). Analysis of ultimate loads of shallow foundations. Journal of Soil Mechanics \& Foundations Div, 99(sm1). 
[26] West, J., \& Stuart, J. (1965). Oblique loading resulting from interference between surface footings on sand. Paper presented at the Proceedings of the 6th international conference on soil mechanics and foundation engineering, Montreal.

[27] Xiao, Y., Zhao, M., \& Zhao, H. (2018). Undrained stability of strip footing above voids in two-layered clays by finite element limit analysis. Computers and Geotechnics, 97, 124-133.

[28] Zhang, R., Chen, G., Zou, J., Zhao, L., \& Jiang, C. (2019). Study on roof collapse of deep circular cavities in jointed rock masses using adaptive finite element limit analysis. Computers and Geotechnics, 111, 42-55. 